\title{
ANALISIS FINANSIAL HUTAN TANAMAN CAMPURAN MERANTI MERAH (Shorea spp.) DAN KARET RAKYAT (Hevea brasiliensis) DI HINAS KIRI KALIMANTAN SELATAN
}

\author{
(Financial Analysis of Red Meranti (Shorea spp.) and Rubber (Hevea brasiliensis) \\ Mixed Forest Plantation in Hinas Kiri South Kalimantan) \\ Kushartati Budiningsih ${ }^{1)}$ dan/and Rachman Effendi ${ }^{2)}$ \\ 'Balai Penelitian Kehutanan Banjarbaru \\ J1 A.Yani Km 28,7 Landasan Ulin, Banjarbaru, Kalimantan Selatan \\ Telp./Fax. 0511-4707872 \\ ${ }^{2}$ Pusat Litbang Perubahan Iklim dan Kebijakan \\ Jl. Gunung Batu No. 5 Po. Box. 272, Bogor 16610 \\ Telp. 0251-8633944 Fax. 0251-8634924
}

Naskah masuk : 16 Februari 2012; Naskah diterima : 30 November 2012

\begin{abstract}
Up to the present, the development of timber-producing forest plantations is not yet optimal and requires a relatively long time. The purpose of this study is to analyze the financial feasibility of red meranti (Shore spp.) cultivation on households scale. Research object selected is red meranti plants which have been developed by community in the village of Hinas Kiri, Batang Alai District, Kabupaten Hulu Sungai Tengah, South Kalimantan. Based on cost benefit analysis, the results showed that the cultivation of red meranti mixed cropping with rubber (Hevea brasiliensis) at the interest rate of 12\% value obtained of NPV is of Rp 14,359,207.00, BCR of 2.70 and IRR of 18\%. Cultivation is very sensitive to decreases in both production quantities and prices of rubber latex sap. This shows that the financial aspects of the cultivation of red meranti mixed cropping with rubber feasible to be developed.
\end{abstract}

Keywords: Plantation forest, red meranti,financial feasibility, cost benefit analysis

\begin{abstract}
ABSTRAK
Sampai saat ini pembangunan hutan tanaman penghasil kayu pertukangan belum optimal. Usaha hutan tanaman penghasil kayu pertukangan memang membutuhkan waktu yang relatif lama. Penelitian ini dilakukan untuk menganalisis kelayakan finansial usaha budidaya hutan tanaman penghasil kayu pertukangan jenis pola campuran dengan karet (Hevea brasiliensis) pada skala rumah tangga. Objek penelitian yang dipilih adalah tanaman meranti merah yang dikembangkan masyarakat di Desa Hinas Kiri Kecamatan Batang Alai Timur Kabupaten Hulu Sungai Tengah. Hasil penelitian menunjukkan bahwa berdasarkan analisis biaya manfaat usaha budidaya meranti campuran karet yang dilakukan pada tingkat suku bunga 12\% diperoleh nilai NPV sebesar Rp14.359.207 dengan nilai BCR 2,70 dan IRR 18\%. Usaha budidaya ini sangat sensitif terhadap penurunan baik jumlah produksi getah karet maupun harga getah. Hal tersebut menunjukkan bahwa dari aspek finansial usaha budidaya meranti merah campuran karet layak untuk dikembangkan.
\end{abstract}

Kata kunci : Hutan tanaman, meranti merah, kelayakan finansial, analisis biaya manfaat

\section{PENDAHULUAN}

Ada kecenderungan bahwa kebutuhan kayu senantiasa meningkat dari tahun ke tahun sementara ketersediaan kayu dari sumber alamnya senantiasa menurun. Hal tersebut dapat terlihat dari hasil simulasi Sumardjani dan Waluyo (2007) dalam telaah analisa konsumsi kayu nasional bahwa permintaan kayu bulat untuk industri kayu olahan seperti kayu pertukangan, block board, veneer, chip wood dan pulp kecuali kayu lapis akan senantiasa meningkat hingga 2014 (jangka waktu analisis yang digunakan) mencapai $115.633 .444 \mathrm{~m}^{3} /$ tahun, sedangkan ketersediaan kayu bulat cenderung mengalami penurunan dan hanya mampu menyediakan $13.873 .734 \mathrm{~m}^{3} /$ tahun. 
Terkait dengan kebutuhan kayu, maka beberapa jenis pohon banyak yang dimanfaatkan untuk memenuhi kebutuhan kayu: salah satunya jenis meranti termasuk penghasil kayu bernilai ekonomi tinggi, disamping jenis lainnya dalam satu famili seperti Keruing, Kapur, Mersawa, Merawan, Bangkirai dan Balau. Dalam satu dasawarsa terakhir, pembangunan tanaman meranti telah dilakukan oleh perusahan-perusahan HTI seperti PT ITCI di Kalimantan Timur dan PT Inhutani II di Kalimantan Selatan. Penanaman meranti selain dilakukan oleh perusahaan ada juga masyarakat yang menanam meranti.

Masyarakat lokal di Desa Hinas Kiri Kecamatan Batang Alai Timur Kabupaten Hulu Sungai Tengah Propinsi Kalimantan Selatan. Pembangunan tanaman meranti di lahan milik sendiri diinisiasi melalui program Gerhan 6 tahun yang lalu. Apakah budidaya meranti ini secara finansial layak untuk dikembangkan? mengingat tanaman meranti memiliki daur yang panjang. Informasi kelayakan finansial budidaya meranti sangat berarti bagi masyarakat sebagai salah satu dasar pertimbangan dalam pengambilan keputusan untuk mengembangkan tanaman meranti di lahan miliknya.

\section{BAHAN DAN METODE}

Penelitian ini dilakukan di Desa Hinas Kiri Kecamatan Batang Alai Timur Kabupaten Hulu Sungai Tengah. Desa ini berlokasi di kaki Pegunungan Meratus, salah satu kawasan lindung yang berada di Kalimantan Selatan. Pemilihan lokasi di dasarkan pada aktivitas masyarakat lokal yang mengembangkan tanaman meranti di kebunnya. Penelitian dilakukan pada bulan Mei Juni 2010.

Data yang digunakan dalam penelitian ini adalah data sekunder dan data primer. Data sekunder yang dikumpulkan mengenai profile desa dan hasil-hasil penelitian menyangkut tanaman meranti dan karet terutama aspek budidaya dan produktivitas. Data primer diperoleh dengan menggunakan metode wawancara dan observasi lapang. Pertanyaan yang diajukan kepada 30 responden, yang dipilih secara purposive, diantaranya kepemilikan lahan, teknik budidaya, komponen biaya pembangunan tanaman, hasil produksi dari tanaman, harga komoditi, pemasaran hasil panen, tenaga kerja yang digunakan dan lainnya.
Data primer selanjutnya diolah dan dianalisis secara deskriptif untuk mengetahui kelayakan finansial dari usaha budidaya meranti campuran dengan karet. Tiga indikator kelayakan finansial yang digunakan adalah NPV (Net Present Value), BCR (Benefit Cost Ratio) dan IRR (Internal Rate of Return).

\section{HASIL DAN PEMBAHASAN}

\section{A. Hasil}

\section{Sejarah Singkat dan Profil Tanaman}

Berdasarkan historinya, penanaman pohon meranti oleh masyarakat lokal di Desa Hinas Kiri tidak terlepas dari proyek Gerhan yang berlangsung pada 2003-2004. Saat itu masyarakat diberi bibit jenis meranti, mahoni, jati, dan beberapa jenis pohon penghasil buah untuk ditanam di lahannya. Respon masyarakat terhadap penanaman pohon meranti beragam. Sebagian ada yang menanam di sela-sela dalam tegakan karet berumur muda ( $<5$ tahun), di areal perladangan atau di semak belukar. Itu tergantung pada tingkat kesiapan lahan petani saat proyek turun.

Kebutuhan bibit meranti dalam proyek gerhan dipenuhi dari persemaian lokal. Persemaian ini dikelola kelompok tani lokal yang pada awalnya memproduksi bibit meranti untuk kepentingan rehabilitasi di Pegunungan Meratus.

Saat ini pohon meranti yang ditanam petani di kebun-kebun masyarakat lokal telah berusia 6 - 7 tahun dengan pola tanam umumnya dicampur dengan pohon karet. Tanaman karet dikembangkan di lahan-lahan milik yang berfungsi sebagai sumber pendapatan harian masyarakat.

Tampilan tegakan meranti yang ada di Hinas Kiri bervariasi. Dalam kebun yang rapat (jumlah pohon $>1.000$ pohon/ha) rata-rata ukuran diameter dan tinggi pohon meranti berkisar $6,2-6,9 \mathrm{~cm}$ dan 8,7-10,0 m. Namun pada kebun dengan jarak tanam pohon lebih teratur dan tidak terlalu rapat, rata-rata ukuran diameter dan tinggi pohon meranti berkisar 12,1 - 15,8 cm dan 12,2 $13,4 \mathrm{~m}$.

Pencapaian kualitas tegakan meranti yang baik tentunya memerlukan pengaturan ruang tumbuh pohon yang sesuai. Terkait dengan hal tersebut, pola tanam menjadi penting dalam membangun tegakan meranti. Pola tanam yang dikembangkan di Hinas Kiri disesuaikan dengan praktek perladangan sebagai bentuk pemanfaatan lahan tradisional seperti yang tampak pada 


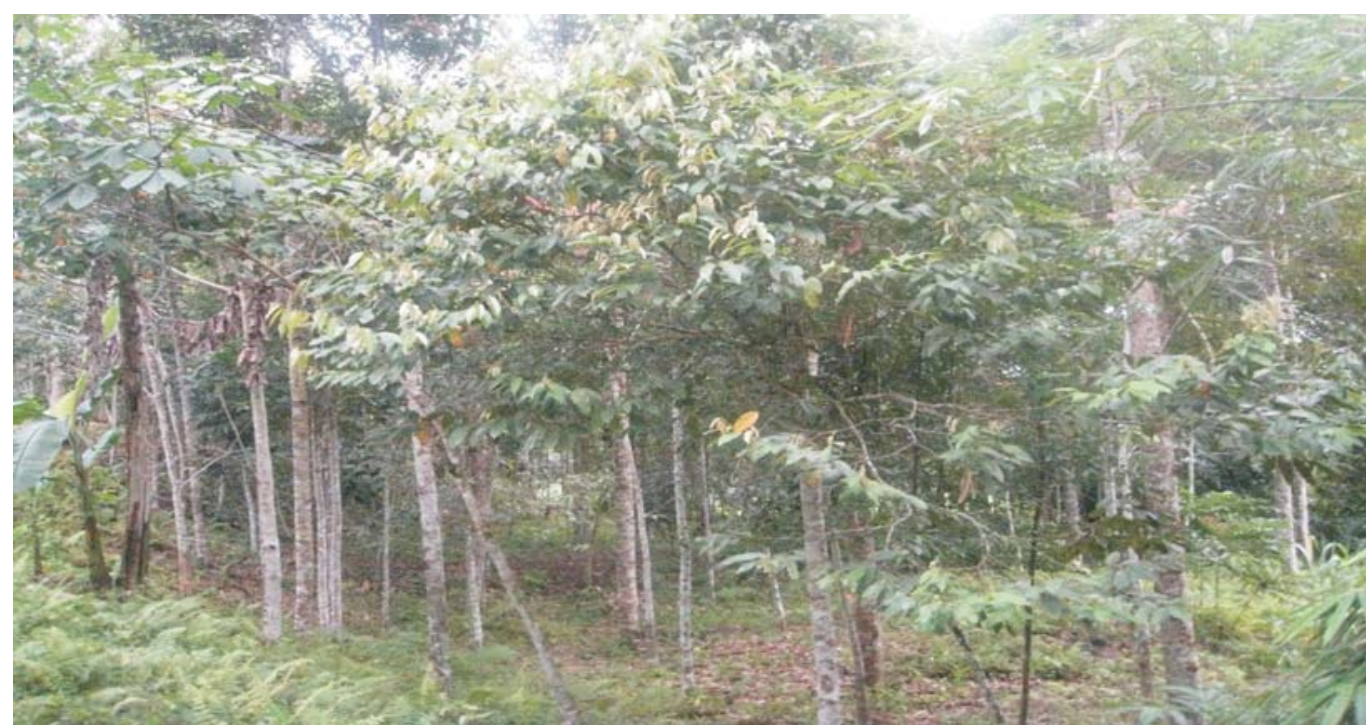

Gambar(Figure) 1. Salah satu profil tanaman meranti campuran karet rakyat di Hinas Kiri(One profile of meranti and rubber plant mixed in Hinas Kiri)

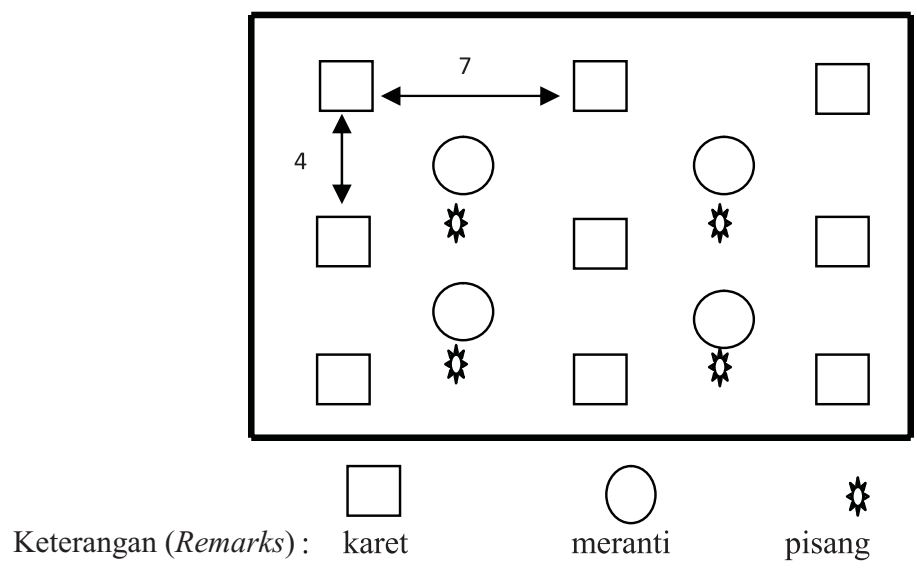

Gambar (Figure) 2. Pola tanam campuran meranti karet (Mixed patterns of meranti and rubber planting)

Gambar 2. Jumlah pohon 1 ha dengan pola tanam seperti itu adalah 390 pohon meranti dan 350 pohon karet.

Tanaman pisang dikelola hingga tahun ke-3 karena produktivitas hasil pisang sudah berkurang selain itu juga guna memberikan ruang tumbuh yang optimal bagi tanaman meranti dan karet.

\section{Analisis Pengusahaan Meranti Campuran Karet}

\section{a. Biaya produksi}

Usaha budidaya tanaman meranti campuran karet dibangun secara bertahap dimulai dari pengadaan peralatan produksi dan bibit, persiap- an lahan, penanaman, pemeliharaan dan pemanenan. Rincian dari tahapan kegiatan usaha budidaya tanaman meranti campuran karet disajikan Tabel 1.

Aktivitas yang dilakukan dalam pembangunan tanaman meranti hingga tanaman dipanen memerlukan sejumlah biaya. Sejumlah biaya yang dikeluarkan terkait dengan pembangunan usaha tanaman meranti campuran karet merupakan biaya produksi. Rincian biaya produksi tanaman meranti campuran karet seluas 1 ha dengan daur 30 tahun tampak pada Tabel 2.

Komponen biaya terbesar dalam pembangunan tanaman meranti campuran karet terkonsentrasi pada biaya pemeliharaan meliputi pemupukan dan penyiangan. Pemeliharaan tanaman berupa pemupukan untuk tanaman meranti di- 
Tabel(Table)1. Deskripsi kegiatan pembangunan tanaman meranti campuran karet (Description of establishment mixed crop meranti and rubber)

\begin{tabular}{|c|c|c|}
\hline $\begin{array}{c}\text { Tahun ke- } \\
(\text { Year })\end{array}$ & $\begin{array}{l}\text { Kegiatan } \\
\text { (Activity) }\end{array}$ & $\begin{array}{l}\text { Deskripsi Kegiatan } \\
\text { (Description of Activity) }\end{array}$ \\
\hline \multirow[t]{3}{*}{1} & Pengadaan peralatan produksi dan bibit & $\begin{array}{l}\text { Peralatan : parang, cangkul dan penyemprot punggung. } \\
\text { Bibit yang dibeli bibit cabe, pisang, karet dan meranti. }\end{array}$ \\
\hline & $\begin{array}{l}\text { Persiapan lahan dan penanaman pisang } \\
\text { dan cabe }\end{array}$ & $\begin{array}{l}\text { Persiapan lahan : penebasan semak belukar lalu dibakar } \\
\text { secara terkendali. Setelah dibakar ada pengajiran. } \\
\text { Pisang ditanam tertutup tanah sebelum lahan dibakar } \\
\text { dan benih cabe ditabur setelah lahan dibakar. }\end{array}$ \\
\hline & Penanaman karet dan meranti & $\begin{array}{l}\text { Karet dan meranti ditanam sesuai dengan ajir yang } \\
\text { telah dipasang. }\end{array}$ \\
\hline \multirow[t]{2}{*}{2} & Pemanenan cabe dan pisang & $\begin{array}{l}\text { Cabe rawit dapat dipanen saat berumur } 3 \text { bulan dengan } \\
\text { frekuensi panen selama } 1-2 \text { minggu sekali hingga cabe } \\
\text { berumur maksimal } 2 \text { tahun. Pisang dipanen saat } \\
\text { berumur } 8 \text { bulan hingga tanaman berumur } 3 \text { tahun. }\end{array}$ \\
\hline & Pemeliharaan meranti dan karet & $\begin{array}{l}\text { Pemeliharaan berupa penyiangan dan pemupukan } \\
\text { sebanyak } 2 \text { kali dalam setahun. }\end{array}$ \\
\hline \multirow[t]{2}{*}{3} & Pemanenan pisang & $\begin{array}{l}\text { Pisang masih dapat dipanen hasilnya hingga berumur } 3 \\
\text { tahun, selanjutnya pisang dimatikan khawatir menjadi } \\
\text { pesaing bagi pertumbuhan pohon meranti. Keberadaan } \\
\text { pohon pisang hanya baik untuk pertumbuhan meranti } \\
\text { muda. }\end{array}$ \\
\hline & Pemeliharaan meranti dan karet & $\begin{array}{l}\text { Pemeliharaan meranti dan karet berupa penyiangan dan } \\
\text { pemupukan sebanyak } 2 \text { kali dalam setahun. Tanaman } \\
\text { meranti selanjutnya tidak dipupuk. }\end{array}$ \\
\hline 4 & Pemeliharan karet & $\begin{array}{l}\text { Pemeliharaan tanaman berupa pemupukan pada karet } \\
\text { dilakukan hingga karet sudah tidak produktif lagi. } \\
\text { Penyiangan tanaman (karet dan meranti) dengan } \\
\text { menggunakan herbisida sebanyak } 1 \text { - } 2 \text { kali dalam } \\
\text { setahun. }\end{array}$ \\
\hline \multirow[t]{2}{*}{$7-25$} & Pemanenan getah karet & $\begin{array}{l}\text { Pemanenan getah karet dimulai pada umur } \& \text { tahun } \\
\text { hingga tahun ke- } 25 \text {. }\end{array}$ \\
\hline & Pemeliharaan karet & $\begin{array}{l}\text { Karet tetap dipelihara dengan pemupukan dan } \\
\text { penyiangan }\end{array}$ \\
\hline 30 & Pemanenan kayu meranti dan karet & $\begin{array}{l}\text { Pemanenan kayu meranti, petani dengan keterbatasan } \\
\text { modal hanya menjual kayu di kebun }\end{array}$ \\
\hline
\end{tabular}

Tabel(Table) 2. Biaya produksi tanaman campuran meranti dan karet rakyat per hektar. (Mixed crop production costs per hectare of meranti and rubber)

\begin{tabular}{|c|l|c|}
\hline $\begin{array}{c}\text { No } \\
\text { (Number) }\end{array}$ & \multicolumn{1}{|c|}{$\begin{array}{c}\text { Uraian } \\
\text { (Description) }\end{array}$} & $\begin{array}{c}\text { Jumlah Biaya (Rp) } \\
\text { (Total Cost (Rp) })\end{array}$ \\
\hline 1 & Pembangunan pondok kerja dan peralatan & 3.442 .300 \\
& (Construction work and equipment) & 1.000 .000 \\
2 & Persiapan lahan (Land preparation) & 2.786 .000 \\
3 & Pembelian bibit (Purchase of seeds) & 636.000 \\
4 & Penanaman (Planting) & 150.520 .000 \\
5 & Pemeliharaan (Maintenance) & 158.384 .300 \\
\hline & TOTAL (Total) & \\
\hline
\end{tabular}

Sumber (Sources) : data primer (diolah,2010) (primary data (processed, 2010)) 
lakukan hingga tahun ketiga. Sementara untuk tanaman karet dilakukan hingga akhir masa produksi karet pada umur ke-25 tahun dengan dosis yang disesuaikan dengan kebutuhan tanaman tersebut. Pembangunan tanaman meranti karet campuran ini dilakukan di lahan milik sehingga biaya tetap dan biaya variabel yang menyangkut lahan tidak dimasukkan.

\section{b. Pendapatan dan keuntungan}

Pendapatan potensial dari usaha budidaya meranti karet bersumber dari produksi tanaman pertanian seperti cabe dan pisang, produksi karet yakni getah karet dan kayu bakar serta produksi meranti berupa kayu pertukangan. Rincian pendapatan yang dapat diperoleh dari usaha budidaya tanaman campuran meranti karet terlihat pada Tabel 3

Pada tahun ke-2 dan ke-3 dari tanaman campuran meranti karet, hasil diperoleh dari tanaman cabe dan pisang. Harga komoditi di pasar lokal untuk karet dan pisang adalah Rp 5.000/liter dan
Rp 15.000/tandan. Hasil getah diperoleh saat tanaman berumur 7 tahun. Produksi getah karet terus berlanjut hingga umur tanaman 25 tahun. Pada akhir daur, petani dapat memperoleh hasil kayu baik dari meranti maupun karet. Petani menjual pohon meranti berdiri di kebun kepada pembeli dengan harga lokal Rp 500.000/m3. Sedangkan kayu karet dijual dengan harga $\mathrm{Rp}$ 60.000 per pohon. Harga ini didekati dengan potensi pohon untuk menghasilkan kayu bakar.

Sementara itu keuntungan usaha budidaya tanaman campuran meranti karet sangat tergantung dari total biaya produksi, jumlah produksi dan harga jual dari komoditi yang ada dalam tanaman campuran tersebut. Berdasarkan Tabel 2 dan Tabel 3 nampak bahwa pendapatan potensil yang dapat diterima petani lebih besar total biaya produksi tanaman campuran meranti karet. Namun hal ini perlu dianalisis dengan memasukkan unsur discount factor karena jangka waktu usaha yang sangat panjang dimana terdapat perbedaan waktu antara pengeluaran dan pendapatan.

Tabel(Table) 3. Nilai produksi dan pendapatan dari budidaya meranti dan karet per hektar (Value of production and revenue of meranti and rubber cultivation per hectare)

\begin{tabular}{|c|c|c|c|c|c|c|c|}
\hline $\begin{array}{c}\text { Tahun } \\
\text { ke- } \\
\text { (Year) }\end{array}$ & $\begin{array}{l}\text { Jenis } \\
\text { Produk } \\
\text { (Product } \\
\text { Type) }\end{array}$ & $\begin{array}{l}\text { Produksi per } \\
\text { thn } \\
\text { Production } \\
\text { /year }\end{array}$ & $\begin{array}{c}\text { Pendapatan(R } \\
\mathrm{p} / \mathrm{th}) \\
(\text { Revenue } \\
(\mathrm{Rp} / \text { year }))\end{array}$ & $\begin{array}{c}\text { Tahun } \\
\text { ke- } \\
\text { (Year) }\end{array}$ & $\begin{array}{c}\text { Jenis Produk } \\
\text { (Product } \\
\text { Type) }\end{array}$ & $\begin{array}{l}\text { Produksi per } \\
\text { thn } \\
\text { (Production/ } \\
\text { year) }\end{array}$ & $\begin{array}{c}\text { Pendapatan } \\
\text { (Rp/th) } \\
\text { (Revenue } \\
\text { (Rp/year)) }\end{array}$ \\
\hline \multirow[t]{2}{*}{2} & Cabe & 120 liter & 600.000 & 16 & Getah & $15.390 \mathrm{~kg}$ & 15.390 .000 \\
\hline & Pisang & 260 tandan & 3.900 .000 & 17 & Getah & $15.560 \mathrm{~kg}$ & 15.560 .000 \\
\hline \multirow[t]{2}{*}{3} & Cabe & 60 liter & 300.000 & 18 & Getah & $14.680 \mathrm{~kg}$ & 14.680 .000 \\
\hline & Pisang & 350 tandan & 5.250 .000 & 19 & Getah & $13.865 \mathrm{~kg}$ & 13.865 .000 \\
\hline 4 & - & - & - & 20 & Getah & $13.280 \mathrm{~kg}$ & 13.280 .000 \\
\hline 5 & - & - & - & 21 & Getah & $13.535 \mathrm{~kg}$ & 13.535 .000 \\
\hline 6 & - & - & - & 22 & Getah & $12.955 \mathrm{~kg}$ & 12.955 .000 \\
\hline 7 & Getah & - & - & 23 & Getah & $12.520 \mathrm{~kg}$ & 12.520 .000 \\
\hline 8 & Getah & $10.800 \mathrm{~kg}$ & 10.800 .000 & 24 & Getah & $11.630 \mathrm{~kg}$ & 11.630 .000 \\
\hline 9 & Getah & $14.320 \mathrm{~kg}$ & 14.320 .000 & 25 & Getah & $11.730 \mathrm{~kg}$ & 11.730 .000 \\
\hline 10 & Getah & $16.205 \mathrm{~kg}$ & 16.205 .000 & 26 & Getah & $11.730 \mathrm{~kg}$ & 11.730 .000 \\
\hline 11 & Getah & $17.170 \mathrm{~kg}$ & 17.170 .000 & 27 & - & - & - \\
\hline 12 & Getah & $18.480 \mathrm{~kg}$ & 18.480 .000 & 28 & - & - & - \\
\hline 13 & Getah & $19.710 \mathrm{~kg}$ & 19.710 .000 & 29 & - & - & - \\
\hline 14 & Getah & $18.805 \mathrm{~kg}$ & 18.805 .000 & 30 & Ky Meranti & $240 \mathrm{~m} 3$ & 120.000 .000 \\
\hline 15 & Getah & $16.630 \mathrm{~kg}$ & 16.630 .000 & & Ky Karet & $1050 \mathrm{ikat}$ & 21.000 .000 \\
\hline
\end{tabular}

Sumber (Sources) : data primer (diolah,2010) (primary data (processed, 2010)) 
Tabel(Table) 4. Rekapitulasi analisis sensitivitas usaha budidaya meranti dan karet (Summary of sensitivity analysis of meranti and rubber cultivation)

\begin{tabular}{|c|c|c|c|}
\hline $\begin{array}{c}\text { Indikator } \\
\text { (Indicator) }\end{array}$ & $\begin{array}{c}\text { Harga getah turun 30\% } \\
\text { (Price gum down 30\%) }\end{array}$ & $\begin{array}{c}\text { Produksi Kayu turun 50\% } \\
\text { (Timber Production Down } \\
50 \% \text { ) }\end{array}$ & $\begin{array}{c}\text { Produksi Karet Turun 20\% } \\
\text { (Rubber Productino Down } \\
20 \% \text { ) }\end{array}$ \\
\hline NPV & -302.138 & 12.356 .531 & 4.779 .622 \\
BCR & 2,19 & 2,32 & 2,36 \\
IRR & $12 \%$ & $18 \%$ & $14 \%$ \\
\hline
\end{tabular}

Sumber (Sources) : Data primer (diolah,2010) (primary data (processed, 2010))

\section{c. Kelayakan finansial}

Untuk mempermudah analisis finansial usaha budidaya tanaman campuran meranti karet rakyat didasarkan pada beberapa asumsi diantaranya tanaman meranti dibangun di lahan milik, sehingga biaya tetap menyangkut lahan seperti pembelian tanah atau sewa lahan diabaikan. Tanaman cabe dan pisang sebagai tanaman tumpangsari dipanen pada tahun ke-2 dan ke-3. Getah karet dipanen mulai tanaman berumur 7 tahun hingga 25 tahun. Harga getah karet yang digunakan adalah harga di pasar lokal yakni sebesar Rp 10.000 per kg. Daur meranti ditetapkan 30 tahun didasarkan pada asumsi riap diameter mencapai $1,5 \mathrm{~cm} /$ tahun sehingga pada umur 30 tahun diameter pohon mencapai $45 \mathrm{~cm}$ sehingga dengan tinggi bebas cabang mencapai $12 \mathrm{~m}$ maka volume kayu mencapai $0,8 \mathrm{~m} 3$ per pohon. Perkiraan ukuran diameter batang relatif sama jika dihitung dengan menggunakan rumus y $=0,4677 \mathrm{x}^{1,38}$ (Istomo et al., 1999) bahwa pada umur 30 tahun, ukuran diameter pohon mencapai $50 \mathrm{~cm}$. Harga kayu meranti yang digunakan adalah harga pohon berdiri sebesar Rp 500.000 per $\mathrm{m}^{3}$. Harga pohon berdiri digunakan karena petani tidak mampu membiayai kegiatan menebang pohon dan distribusi kayu ke pasar, di akhir daur, kayu meranti, kayu karet juga ditebang untuk diproduksi sebagai kayu bakar.

Nilai NPV untuk usaha budidaya tanaman campuran meranti karet dengan menggunakan suku bunga efektif $12 \%$ adalah sebesar Rp 14.359.207. Nilai NPV yang positif ini menunjuk-kan usaha budaya tersebut menguntungkan. Sementara itu nilai BCR dari usaha tersebut sebesar 2,70 yang berarti nilai rupiah hasil investasi sebesar 2,70 kali dari nilai rupiah yang diinvestasikan. Nilai BCR $>1$ ini menunjukan bahwa usaha tersebut menguntungkan. Untuk nilai IRR diperoleh sebesar $18 \%$ yang artinya bisnis tanaman karet akan memberikan pendapatan sama dengan biaya yang dikeluarkan jika tingkat suku bunga yang berlaku sebesar $18 \%$. Apabila suku bunga pinjaman lebih dari $18 \%$ persen maka usaha tersebut tidak menguntungkan. Berdasarkan 3 parameter kelayakan finansial, nampak bahwa usaha budidaya tanaman campuran meranti karet menguntungkan sehingga layak untuk dikembangkan.

Kelayakan finansial usaha budidaya tanaman campuran lebih lanjut dianalisis sensitivitasnya. Tabel 4 memperlihatkan analisis sensitivitas terhadap kelayakan finansial usaha budidaya tanaman meranti karet seandainya terjadi perubahan dalam jumlah produksi, harga komoditi dan perubahan suku bunga.

Pada kondisi produksi kayu turun hingga $50 \%$, usaha ini masih memberikan harapan keuntungan sebesar Rp 12.356.531. Namun pada kondisi yang terkait baik harga maupun produksi getah karet, usaha ini menjadi sangat sensitif. Pada kondisi harga karet yang turun 30\% dari harga pasar saat ini, nampak bahwa nilai NPV negatif, artinya usaha ini tidak memberikan harapan keuntungan. Ini dapat terjadi karena biaya pengelolaan jauh lebih besar daripada pendapatan dari getah karet. Pada kondisi produksi karet turun $20 \%$, usaha ini masih memberikan harapan keuntungan sebesar Rp 4.779.622. Namun bila produksi getah karet turun hingga $30 \%$, NPV dari usaha ini menjadi negatif. Dengan demikian usaha budidaya meranti karet ini sangat sensitif terhadap harga getah karet.

\section{B. Pembahasan}

\section{Pilihan kombinasi meranti karet}

Salah satu wujud aktivitas masyarakat lokal pedesaan dalam pemanfaatan lahan tradisional yakni penanaman pohon. Penanaman pohon tersebut akan terintegrasi dengan praktek perladangan. Jenis karet merupakan jenis yang paling banyak dikembangkan masyarakat pedesaan di Indonesia begitupula di Desa Hinas Kiri. Kemampuan tanaman karet berperan sebagai sumber pendapatan harian rumah tangga menjadi alasan utama masyarakat membudidayakan jenis ini, disamping karet mudah beradaptasi dengan kondisi lingkungan. 
Sementara itu penanaman jenis pohon umumnya dapat diproduksi dalam jangka waktu yang panjang. Jenis meranti merah (Shorea $s p$ ) sebagai penghasil kayu pertukangan diproduksi setelah mencapai 30 tahun. Bagi masyarakat Hinas Kiri, jika meranti ditanam secara khusus khawatir tanaman tidak akan dipelihara. Namun berbeda jika meranti dicampur dengan karet, ketika petani baik memelihara (memupuk dan menyiangi) maupun menyadap karet, tanaman meranti pun secara tidak langsung ikut terpelihara.

Ditinjau dari penampilan, pencampuran meranti dan karet ini tidak menghadapi kendala dalam struktur tegakan. Pohon meranti memiliki model tajuk seperti mahkota (crown canopy) sehingga tajuknya tidak akan menaungi pohon karet. Oleh karena itu jika ditinjau dari model tajuk penanaman meranti yang dikombinasikan dengan karet merupakan pilihan yang sesuai untuk kondisi ekologis, sosial dan budaya masyarakat di Hinas Kiri. Integrasi meranti dalam kebun karet seperti ini juga terjadi di Kabupaten Bungo, Jambi (Tata el al., 2008). Integrasi berbagai jenis pohon baik pohon penghasil kayu maupun buah ke dalam kebun karet menjadikan wanatani karet lebih produktif(Akiefnawati et al., 2008).

Ditinjau dari nilai ekonomi, kasus di Hinas Kiri, maka berdasarkan Tabel 3 pendapatan hasil dari getah karet berkontribusi sebesar 65\% dari nilai ekonomi total budidaya meranti karet. Jika dibandingkan dengan tanaman monokultur meranti, hasil penelitian sejenis menunjukkan bahwa kelayakan finansial meranti yang dikelola secara monokultur dengan skala perusahaan pada tingkat suku bunga 8\% nilai NPV sebesar Rp 5.550.948 sementara pada tingkat suku bunga 10\% NPV-nya bernilai negatif (Yuniati dan Suastati, 2008).

\section{Kebutuhan investasi dan proyeksi laba rugi}

Berdasarkan analisis terhadap biaya produksi dan tahapan kegiatan pembangunan tanaman meranti karet dapat diketahui kebutuhan investasi petani terhadap usaha budidaya tersebut. Pada tahun pertama, investasi yang diperlukan sebesar Rp 6.117.000 untuk keperluan penyiapan lahan, pembelian bibit, peralatan dan bahan produksi lainnya. Lebih lanjut hingga tahun ke-8, saat petani mulai memperoleh hasil dari getah karet, investasi yang diperlukan mencapai Rp. 47.013.700.

Apabila kebutuhan investasi usaha tersebut dipenuhi selain dari modal sendiri juga dipenuhi dari pinjaman bank maka secara otomatis usaha ini terbebani dengan biaya bunga sehingga investasi kegiatan ini menjadi lebih besar. Andaikan kebutuhan investasi dipenuhi dari pinjaman Bank sebesar 65\% kewajiban finansial sebesar Rp 29.336.548 (12\% x 8 x 0.65 $x$ Rp. 7.013.700), sehingga total kebutuhan modal investasi untuk kegiatan usaha tanaman meranti karet selama 8 tahun adalah sebesar Rp 76.350.248. Sebenarnya pada tahun ke-2 dan ke-3 ada pendapatan dari cabe dan pisang sejumlah Rp 10.000.000. Dengan demikian kebutuhan total investasi hingga tahun ke-8 sebesar Rp 66.350.248.

Proyeksi laba rugi usaha tanaman campuran meranti karet selama jangka waktu pengusahaan terlihat pada Tabel 5. Berdasarkan proyeksi laba rugi nampak bahwa secara kumulatif nilai laba rugi hingga tahun ke-10 masih negatif. Menginjak tahun ke-11, nilai laba rugi sudah positif. Namun seandainya $65 \%$ investasi dipenuhi dari pinjaman bank, petani masih terbebani kewajiban finansial sebesar Rp 29.336.548. Sehingga pada tahun ke-14 hingga akhir daur petani dapat menikmati keuntungan bersih.

Tabel(Table) 5. Proyeksi laba rugi usaha budidaya meranti karet seluas 1 ha (Profit and loss projection of meranti and rubber cultivation per hectare)

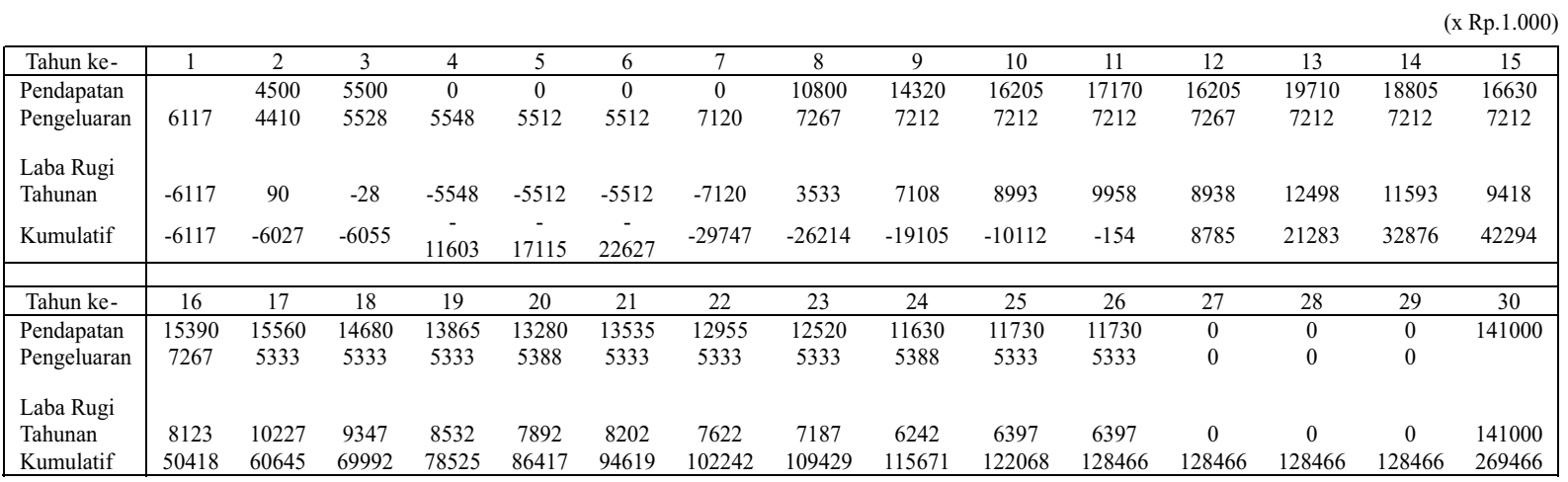

Sumber (Sources) : data primer (diolah,2010) (primary data (processed, 2010)) 


\section{Kontribusi Nyata Pemerintah Daerah}

Berdasarkan hasil analisis finansial bahwa usaha budidaya meranti campuran karet layak dikembangkan oleh masyarakat di Hinas Kiri. Namun usaha budidaya tersebut membutuhkan dana yang tidak kecil, pada awal tahun membutuhkan dana sebesar Rp 6.117.000 sementara total investasi yang diperlukan hingga tahun ke- 8 sebesar Rp 47.013.700.

Terkait dengan investasi, kondisi umum yang dihadapi masyarakat pedesaan khususnya masyarakat di dalam dan sekitar hutan adalah keterbatasan modal. Disisi lain, usaha budidaya pohon skala usahatani pada umumnya selain berfungsi ekonomis bagi perekonomian rumah tangga juga mempunyai fungsi ekologis bagi lingkungan. Kondisi ini terjadi juga dengan penanaman campuran meranti karet di Hinas Kiri yang mempunyai fungsi ekonomis dan ekologis. Wilayah Desa Hinas Kiri berada di kaki Pegunungan Meratus mempunyai peran penting dalam mendukung kelestarian fungsi Pegunungan Meratus sebagai Kawasan Lindung. Oleh karena itu dalam pengembangan hutan tanaman meranti selanjutnya kontribusi nyata Pemda tetap sangat diharapkan oleh masyarakat.

\section{KESIMPULAN}

Berdasarkan analisis biaya manfaat usaha budidaya campuran meranti karet yang dilakukan pada tingkat suku bunga 12\% menghasilkan nilai NPV sebesar Rp 14.359.207 dengan nilai BCR 2,70 dan IRR 18\%. Berdasarkan nilai dugaan dari ketiga parameter kelayakan finansial tersebut, maka usaha budidaya campuran meranti karet skala rumah tangga secara finansial layak dikembangkan.

Hasil analisis sensitivitas terhadap kelayakan finansial menunjukkan bahwa usaha tersebut sangat sensitif terhadap penurunan jumlah produksi dan harga getah karet. Usaha budidaya meranti karet menjadi tidak layak dikembangkan jika terjadi penurunan jumlah produksi getah sebanyak 30\% atau harga getah karet turun menjadi Rp.7.000/kg.
Kebutuhan investasi usaha budidaya meranti karet pada tahun pertama sebesar $\mathrm{Rp}$ 6.117.000,00. Sedangkan kebutuhan investasi pada tahun ke-8 dimana karet sudah mulai produksi sebesar Rp 47.013.700,00. Terkait dengan kebutuhan investasi usaha, masyarakat secara individual memiliki keterbatasan modal.

Budidaya meranti karet menunjukkan fungsi ekonomis sebagai sebuah usaha bagi rumah tangga selanjutnya berkontribusi terhadap lingkungan. Apresiasi Pemerintah Daerah setempat terhadap usaha ini sangat berarti dalam pengembangan budidaya campuran meranti karet selanjutnya.

\section{DAFTAR PUSTAKA}

Akiefnawati, R., G. Wibawa, L. Joshi dan Mv. Noordwijk. Meningkatkan Produktivitas Karet Rakyat melalui Sistem Wanatani. (eds). 2008. dalam Belajar Dari Bungo : Mengelola Sumber-daya Alam di Era Desentralisasi. Cifor. Bogor.

Istomo, C.Wibowo dan N. Hidayati. 1999. Evaluasi Pertumbuhan Tanaman Meranti (Shorea spp) di Haurbentes BKPH Jasinga KPH Bogor Perum Perhutani Unit III Jawa Barat. Jurnal Manajemen Hutan Tropika Vol V No 2 :13-22.

Sumardjani. L. dan S.D. Waluyo. 2007. Analisa Konsumsi Kayu Nasional. Akses tanggal 11 September 2011. http://www. rimbawan.com.

Tata, L., Mv. Noordwijk. S. Rasnovi dan L. Joshi. Pengayaan Jenis Wanatani Karet dengan Meranti. (eds). 2008. dalam Belajar Dari Bungo : Mengelola Sumberdaya Alam di Era Desentralisasi. Cifor. Bogor.

Yuniati, D. dan L. Suastati. 2008. Analisis Finansial Pembangunan Hutan Tanaman Dipterocarpaceae Studi Kasus di PT. Inhutani II Pulau Laut Propinsi Kalimantan Selatan. Jurnal Penelitian Dipterocarpaceae Vol. 2 No.1. 